\title{
Selective sparing of topographical memory
}

\author{
Eleanor A Maguire, Lisa Cipolotti
}

\begin{abstract}
The case of a 61 year old patient with Pick's disease involving predominantly the left temporal lobe, who has been studied over a 5 year period, is reported. She presented with a grave impairment of both verbal and non-verbal memory functions. Her non-verbal memory deficits included profound impairments on the recognition of unfamiliar faces and the recall of abstract designs. Remarkably, her visual recognition memory performance for unknown buildings, landscapes, and outdoor scenes was preserved. Strikingly, her ability to recall familiar routes and learn new ones through a complex virtual reality town was also entirely normal. This seems to be the first case documenting the selective preservation of topographical memory in the context of severe nonverbal and verbal memory impairments. These findings imply that topographical memory and non-verbal memory are subserved by separable neural systems.

(f Neurol Neurosurg Psychiatry 1998;65:903-909)
\end{abstract}

Keywords: topographical memory; Pick's disease; selective preservation

It is widely acknowledged that unilateral damage to the medial temporal lobe can result in modality specific memory impairments. Typically, right medial temporal lobe lesions result selectively in non-verbal memory deficits ${ }^{12}$ whereas left medial temporal lobe lesions result in verbal memory impairments. ${ }^{34}$ Often patients with damage to the right temporal lobe present a non-verbal memory impairment that encompasses poor performance on tests employing various visual memoranda such as the recall of abstract designs, the processing of topographical stimuli, and the recognition of unfamiliar faces. However, the extent to which non-verbal memory impairments can be selectively limited to one class of stimuli has been relatively little investigated. For example, patients have been reported with impairments in memory for abstract visual and spatial designs. ${ }^{5}{ }^{6}$ However, it remains unclear whether such impairments co-occur with deficits in the memory for other non-verbal stimuli such as, for instance, unfamiliar faces or topographical stimuli.

The investigation of patients with impairments in topographical memory has provided some evidence for dissociability between different classes of non-verbal memory. A topographical memory impairment affects a person's ability to find or to learn to find his or her way from one location to another. It can also affect the capacity of the person to recognise familiar landmarks and buildings and to learn to recognise unfamiliar ones. ${ }^{7}$ This condition is often seen in the context of dementia or confusional states or in conjunction with a more limited set of visual perceptual deficits. ${ }^{8-11}$ Typically, patients with topographical memory impairments also present with a deficit in nonverbal memory which extends to other classes of stimuli such as unfamiliar faces as well as abstract visual and spatial patterns. ${ }^{12-15}$

There are, however, on record a few rare cases in which the impairment in topographical memory is reported as highly selective. Some of these patients presented with a specific memory loss for how landmarks spatially relate to each other in large scale space in the context of an intact ability to recognise buildings, landmarks, and landscapes. ${ }^{16}$ By contrast, other patients had an impairment primarily affecting the recognition of both familiar and unknown buildings and landmarks but also their spatial relations. ${ }^{17}{ }^{18}$ Interestingly, these patients with topographical memory deficits did not present a more generalised non-verbal memory impairment, at least as indexed by their satisfactory performance on recognition memory tests using unfamiliar faces. Thus this evidence suggests that an impairment of non-verbal memory can affect one class of item, such as topography, but it does not necessarily extend to other non-verbal classes of stimuli such as unfamiliar faces. The opposite type of nonverbal memory impairment-namely, a deficit in recognising unfamiliar faces with spared recognition of topographical stimuli-has been reported but only in the context of patients with prosopagnosia. ${ }^{19}$ Thus it remains unclear whether topographical memoranda are processed by the same pathway as other non-face visual stimuli-such as abstract visual designs - or whether they are processed by an encapsulated pathway as are faces.

In this study we document for the first time the selective sparing of topographical memory in a patient with Pick's disease. This patient presented with a severe verbal memory impairment affecting both recognition and recall. In addition, she presented a profound non-verbal memory impairment for stimuli including unfamiliar faces and abstract visual designs.

\section{Case report}

The patient was a 61 year old right handed teacher who was first referred to Dr Zilkha in 1992 with a 1 year history of word finding difficulties. Neurological examination was entirely normal except for the cognitive deficit described below. Brain MRI contemporaneous with her final neuropsychological assessment showed generalised cerebral atrophy, particularly marked in the left temporal lobe and 

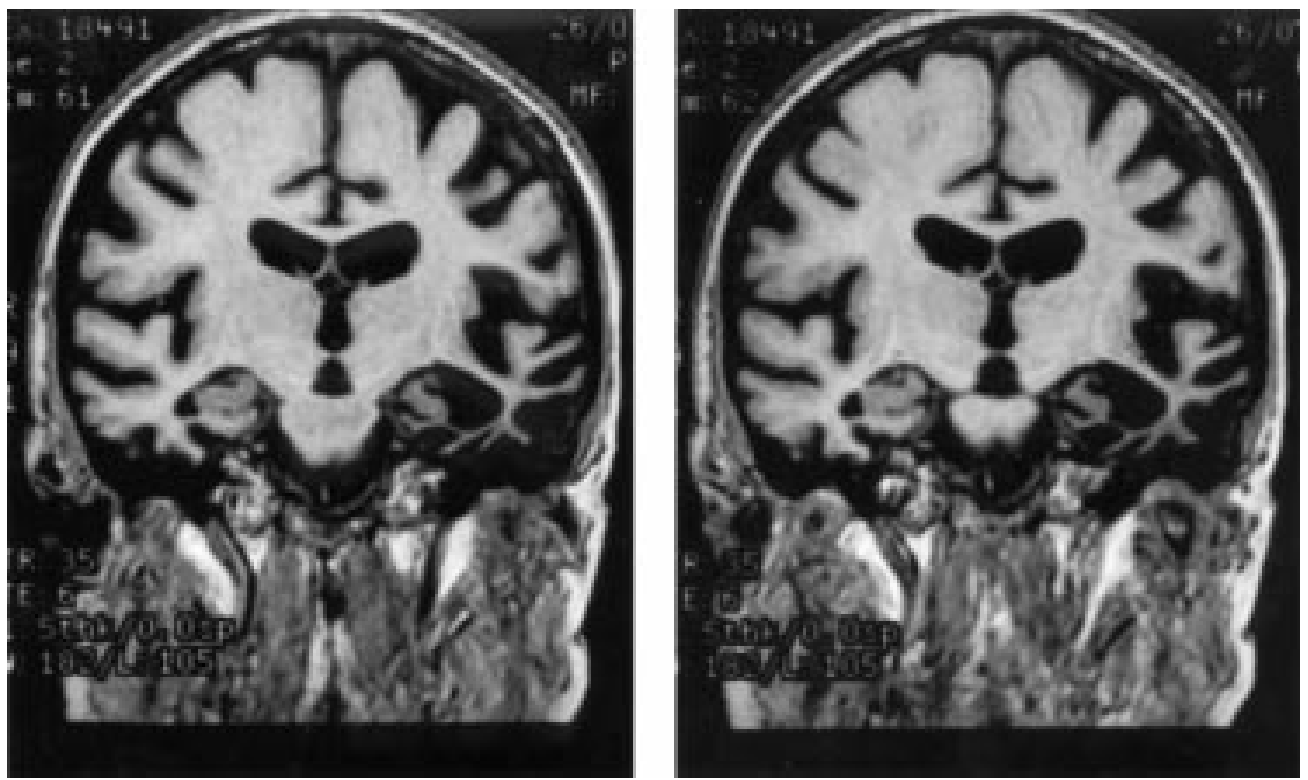

T1 weighted coronal MRI showing contiguous slices: there is mild generalised atrophy with gross atrophy of the left temporal lobe and hippocampus and marked dilatation of the left temporal horn.

involving all left temporal gyri and medial structures. The atrophic changes in the right temporal cortex were considerably less marked than in the left temporal lobe, and commensurate with those seen generally. In comparing the left and right temporal cortex, the atrophic changes on the right did not extend as posteriorly as those on the left. The right medial temporal structures were also clearly less affected than the left medial temporal structures (figure). The clinical diagnosis was probable Pick's disease.

NEUROPSYCHOLOGICAL ASSESSMENT

The patient was first referred to the Neuropsychology Department of the National Hospital for Neurology and Neurosurgery in December 1992 for evaluation of her language difficulties. She has been subsequently reassessed on five occasions. The detailed topographical memory investigation reported here took place at the time of her fifth assessment (April 1997). The results of her five formal neuropsychological assessments are reported in table 1 .

When she was first assessed on the Wechsler adult intelligence scale (WAIS-R) in December 1992 her verbal and performance IQs were average. However, in view of her occupational and educational record, these figures were clearly below her estimated premorbid optimal level of functioning. Her verbal memory functions were found to be selectively weak when compared with her superior visual memory functions. There was also some evidence of word finding difficulties. On the graded naming test her performance was slow, effortful, and in the low average range. However, her visual perceptual functions, as assessed by subtests of the visual object space perception battery ${ }^{20}$ were within the normal range.

Through the second, third, and fourth assessments, her verbal skills deteriorated steadily while her non-verbal cognitive skills remained static at an average level. The two

Table 1 Cognitive test scores

\begin{tabular}{|c|c|c|c|c|c|}
\hline & \multicolumn{5}{|l|}{ Assessment } \\
\hline & $1 s t$ & $2 n d$ & $3 r d$ & $4 t h$ & 5 th \\
\hline & Dec 92 & Sep 93 & $\mathrm{Feb} 94$ & Sep 95 & Apr 97 \\
\hline VIQ & 94 & 89 & 89 & 73 & 58 \\
\hline PIQ & 109 & 99 & 101 & 95 & 92 \\
\hline \multirow[t]{2}{*}{ RM Words } & $44 / 50$ & $43 / 50$ & $39 / 50$ & $39 / 50$ & $33 / 50$ \\
\hline & $50-75 \%$ ile & $50-75 \%$ ile & $10-25 \%$ ile & $10-25 \%$ ile & $<5 \%$ ile \\
\hline \multirow{2}{*}{ RM Faces } & $47 / 50$ & $48 / 50$ & $44 / 50$ & $45 / 50$ & $32 / 50$ \\
\hline & $=95 \%$ ile & $>95 \%$ ile & $50-75 \%$ ile & $=75 \%$ ile & $<1 \%$ ile \\
\hline \multirow{2}{*}{ GNT } & $16 / 30$ & $13 / 30$ & $7 / 30$ & $3 / 30$ & $0 / 30$ \\
\hline & $10-25 \%$ ile & $=5 \%$ ile & $<1 \%$ ile & $<\%$ ile & $<1 \%$ ile \\
\hline ST & - & - & - & - & $\begin{array}{l}36 / 50 \\
10-25 \% \text { ile }\end{array}$ \\
\hline OD & - & - & - & $19 / 20$ & $18 / 20$ \\
\hline CA & - & - & - & $10 / 10$ & $10 / 10$ \\
\hline IL & $20 / 20$ & $20 / 20$ & $20 / 20$ & - & - \\
\hline DC & $20 / 20$ & $20 / 20$ & $20 / 20$ & - & $20 / 20$ \\
\hline NL & - & - & - & - & $9 / 10$ \\
\hline SD & - & - & - & - & $19 / 20$ \\
\hline
\end{tabular}

RM Words=recognition memory for words; RM Faces=recognition memory for faces; $\mathrm{GNT}=$ graded naming test; ST=synonym test; $\mathrm{OD}=$ object decision; $\mathrm{CA}=$ cube analysis; $\mathrm{IL}=$ incomplete letters; $\mathrm{DC}=$ dot centre; $\mathrm{NL}=$ number location; $\mathrm{SD}=$ shape detection; - not tested. 
Table 2 Verbal and non-verbal memory scores

\begin{tabular}{lll}
\hline & $\begin{array}{l}\text { Raw } \\
\text { scores }\end{array}$ & \%iles \\
\hline Alternative recognition memory test for words & $31 / 50$ & $<1$ st \\
Alternative recognition memory test for faces & $32 / 50$ & $<5$ th \\
Easy recognition memory test for words & $18 / 25$ & $<5$ th \\
Easy recognition memory test for faces & $20 / 25$ & $=5$ th \\
Easy paired associates learning & $10 / 48$ & $<5$ th \\
Rey-Osterreith complex figure: & $35 / 36$ & $=90$ th \\
$\quad$ Copy & $5 / 36$ & $<5$ th \\
\hline Delayed & & \\
\hline
\end{tabular}

most notable features were her increasingly severe word finding difficulties and the selective and severe progressive decline of her verbal memory functions. At the time of her fifth neuropsychological assessment, a further decline in her cognitive status was noted. There had been a further significant decline in her verbal IQ, now at a defective level. By contrast, her performance IQ had remained at an average level. Her spontaneous speech was very sparse, marred by profound nominal impairments. She was now virtually unable to orally name to confrontation. Her comprehension at the single word level was assessed on a stringent written two choice synonym test for concrete and abstract words. ${ }^{21}$ She obtained a low average score on this test. Her performance on tests of perception and spatial skills remained at a normal level.

Although there was evidence of a selective verbal memory impairment on the first four assessments, at the time of the fifth assessment a more severe global memory impairment was recorded (table 1). Her performance was found to be severely impaired on a recognition memory task using unfamiliar faces. This impairment was not underpinned by a more general deficit in face processing; she was able to recognise photographs of famous faces flawlessly (12/12).

MEMORY INVESTIGATIONS

At the time of her fifth neuropsychological assessment the patient was still able to attend regular hospital appointments making a long and complicated journey on her own. Often at the end of her hospital appointment she would successfully visit unaccompanied various museums and art exhibitions in London. In addition, she had no difficulty orienting herself within the hospital environment. Indeed, she learned two new routes taking her between departments very rapidly. She still drove her car and could easily learn new routes when driving her husband for weekend trips. These observations clearly contrasted with the finding of a severe and global memory impairment. To explore her memory functions further, the following tests using verbal and visual stimuli, some of which were specifically topographical, were completed.

CONTROL SUBJECTS

Six normal healthy women of comparable age (range 46-57 years) and education (to degree level) to our patient were used as controls on some of the memory tests described below.
RECOGNITION MEMORY FOR WORDS AND FACES To obtain further measures of the patient's verbal and non-verbal recognition memory functions, two recognition memory tests for words and faces of varying difficulty were administered: (1) an alternative version of the standard recognition memory test; (2) a shorter and easier version of the recognition memory test. ${ }^{22}$ Her raw and percentile scores are reported in table 2 . Her performance was gravely impaired on both an alternative version of the recognition memory test and on the easy version of the recognition memory test. This impairment equally affected memory for words and faces. These findings provide a very robust replication of our original finding and suggest that the patient had a grave verbal and non-verbal memory impairment.

RECALL MEMORY FOR WORDS AND VISUAL STIMULI

A verbal and a non-verbal recall task were administered to the patient. The verbal recall memory test was the easy paired associates learning test devised by Clegg and Warrington. ${ }^{22}$ The visual recall memory test was the Rey-Osterreith complex figure. Her results are reported in table 2 . Her performance was gravely impaired on the easy paired associates learning test. On the Rey-Osterreith complex figure her performance was normal in the copy trial condition but severely impaired in the delayed recall condition. These results clearly indicate that the patient presented with severe visual and verbal memory recall impairments in addition to her recognition memory deficits.

SPATIAL LEARNING

Spatial span was assessed with the Corsi block tapping task which required the patient to tap wooden blocks randomly arranged on a tablet in the same order as tapped by the examiner. ${ }^{23}$ On this task her performance was well within the normal range (spatial span seven blocks). After having established her short term memory spatial span, learning was assessed by presenting a supraspan sequence repeatedly (span+two=nine blocks), as described by De Renzi et al. ${ }^{24}$ She learned the sequence in 16 trials, which is well within the average of the normal control group reported by De Renzi et al.

MAZES

The patient was also given a visual maze task. Maze number 7 from the Wechsler intelligence scale for children (WISC-R) was employed. She was requested to trace the path to the exit as quickly as possible. The same maze was repeatedly presented. Her completion time was recorded with a stopwatch. The patient's significant global cognitive impairment and perseverative tendencies meant that it took several attempts to explain the task so that she understood what was required. Her dyspraxia also contributed to a slowing of performance. However, given these limitations, she performed satisfactorily, showing increasingly shorter completion times. It took her 5 minutes 
Table 3 Topographical memory and geographical knowledge scores

\begin{tabular}{|c|c|c|c|}
\hline & \multirow[b]{2}{*}{ Patient scores } & \multicolumn{2}{|c|}{ Control subjects } \\
\hline & & $\begin{array}{l}\text { Mean score } \\
(S D)\end{array}$ & Range \\
\hline \multicolumn{4}{|l|}{ Topographical memory } \\
\hline Topographical recognition memory test & $28 / 30$ (>95th \%ile) & & \\
\hline Recognition memory test for unknown buildings & $39 / 50$ & $42.6^{\star}$ & $35-46^{\star}$ \\
\hline $\begin{array}{l}\text { Recognition memory test for unknown } \\
\text { landscapes }\end{array}$ & $46 / 50$ & $40.2(4.3)$ & $35-47$ \\
\hline Routes: virtual reality town & $9 / 10$ & $8(1.0)$ & $7-9$ \\
\hline \multicolumn{4}{|l|}{ Geographical knowledge: } \\
\hline Landmark location London map & $12 / 14$ & $11.4(1.7)$ & $10-14$ \\
\hline City location United Kingdom map & $7 / 15$ & $10.2(2.2)$ & $6-12$ \\
\hline City location Europe map & $2 / 10$ & $7.8(2.0)$ & $4-9$ \\
\hline City location World map & $2 / 12$ & $7.3(2.7)$ & $4-11$ \\
\hline North/south United Kingdom test & $8 / 11$ & $9.5(0.8)$ & $8-10$ \\
\hline North/south World test & $6 / 14$ & $12(1.7)$ & $10-14$ \\
\hline
\end{tabular}

${ }^{\star}$ Control data taken from Whiteley and Warrington. ${ }^{17}$

35 seconds to complete the first trial. However, at the time of the sixth trial her completion time was only 25 seconds, indicating that she presented with no gross defect on this measure.

TOPOGRAPHICAL MEMORY

Recognition memory for topographical scenes, unknown buildings, and landscapes

The patient was tested on three recognition memory tests each involving topographical memory. These tests were devised to be comparable with the recognition memory test for words and faces but varied in the material and number of items employed. In the topographical recognition memory test, the memoranda are 30 coloured photographs of outdoor topographical scenes. Three alternative forced choice recognition memory tests followed with distractors showing the same scene as the target but from a different angle. ${ }^{25}$ This test is known to be sensitive to right hemispheric lesions. The recognition memory test for unknown buildings has been previously described by Whiteley and Warrington. ${ }^{17}$ The test consists of 50 black and white photographs of previously unknown buildings which are presented to the patient singly at a 3 second rate, the subject responding "yes" or "no" to each according to whether she liked the architecture or not. Two alternative forced choice recognition memory tests follow. This time the distractor item is a different building from the target but one which is architecturally similar to it. The recognition memory for unknown landscapes test is similar in structure and method of administration to the unknown buildings test. It differs in the patient's orientation task and in the material. The memoranda in this task consist of black and white photographs of country scenes which vary from aerial views of coastlines to valleys, mountains, lakes, and rivers (for further details see Whiteley and Warrington ${ }^{17}$ ). The patient responded "yes" or "no" to each photograph according to whether she thought it has been taken in winter or in summer. The patient's performance and the mean scores and range of controls are reported in table 3.

Remarkably, her performance on these tests was very good indeed. She obtained a superior score on the topographical recognition memory test. In addition, her performance was well within the normal range on the recognition memory tests for unknown buildings and landscapes. These results show that the patient's topographical memory skills are far superior to her gravely impaired non-verbal and verbal memory skills.

\section{Routes: virtual reality town}

The topographical memory tests described above, although able to capture some aspects of real world topography, were clearly not designed to assess the dynamic aspects of topographical memory-namely, navigation. The patient's ability to navigate to remembered locations was tested using a computer simulated town (designed by $\mathrm{N}$ Burgess; see Maguire $e t a l^{26}$ for details). She sat in front of a computer monitor which displayed a colour, textured, first person view of a town. She navigated through the town using four keys on the computer keyboard (up, down, left, right). The town contained several streets and numerous buildings - two shops, a church, a large cinema complex, two bars, a train station, an amusement arcade, and a bank. She explored outside and inside all of the buildings, which were interconnected in different ways. She explored the town for as long as she needed so that she felt confident that she knew her way around. After learning, her ability to find her way in the town was tested. She was shown a picture of a place in the town and starting from a different place in the town, she had to find her way to the goal place using the four keys to navigate. During memory testing she was given a total of 10 places to find. Remarkably, her performance on this test was well within the range of our control subjects (table 3). Strikingly, at the end of the testing session, she was also able to draw an accurate map of the broad layout of the town that could be usefully followed by someone unfamiliar with the area.

Thus the patient not only presented with a selective preservation of topographical memory as assessed by static recognition memory tests, but also showed an intact capacity to engage in dynamic and successful navigation in complex environments.

\section{Geographical knowledge}

Geographical knowledge was tested in the patient. An initial investigation focused on her knowledge of geographical location. Four geographical location tests were administered: (1) famous London landmarks; (2) United Kingdom cities; (3) European cities; (4) world cities. For each of these four tests, a blank map was placed in front of the patient and she was asked to indicate the relevant locations by pointing. The mean score and the range of performance of the patient and the control women are presented in table 3. Her scores were well within the control range on the tests of London landmark location and at the lower limit of the control range for United Kingdom cities. By contrast, however, her locating of cities on blank maps of Europe and the world was deficient relative to the control subjects. It is of interest to note that out of the 18 errors made on these last two tests, only four involved misplacing of cities outside 
their correct country boundaries. For example, when asked to indicate the location of the city of Los Angeles, she pointed to a location within the correct country (United States) but incorrectly on the east coast instead of the west. This suggests that she had preserved knowledge at a level superordinate to the specific locations of cities.

Further testing focused on the patient's knowledge of geographical direction (table 3). Two tests of geographical direction were administered: (1) north/south United Kingdom cities; (2) north/south world cities. Testing in both cases involved two cards being placed in front of her, one depicting the word "north" the other the word "south". In the north/south United Kingdom cities test, cards with names of British cities were shown to her one at a time. She was required to indicate whether the city was north or south of London by placing the name of the city under the name of the card north or south. In the north/south world cities test, she was asked to indicate if well known world cities were north or south of England by placing city names under the north/south cards. Confirming the differential performance noted in the four geographical location tests outlined above, her performance was at the lower limits of the control range for the English cities but clearly more impaired for world cities.

\section{Discussion}

In this study we have described an investigation of the memory skills of a patient with Pick's disease who has been followed up over a 5 year period. The topographical memory investigations reported here were carried out at the time of her fifth assessment. By this time, she was exhibiting a grave impairment of language; she had very sparse spontaneous speech, was virtually unable to name to confrontation, and had mild word comprehension difficulties. Her memory functions, which had originally been characterised by a selective loss of verbal memory, had progressively deteriorated to become globally and gravely affected for verbal and non-verbal material at the time of this report. Her performance was profoundly impaired on three tests of varying difficulty of recognition memory for words and on a verbal recall memory test. Similarly, on three tests of varying difficulty of recognition memory for unfamiliar faces her performance was severely impaired. Her visual memory recall as indexed by the Rey-Osterreith complex figure test was also impaired. Her severe non-verbal memory impairment affecting both recognition and recall could not be accounted for in terms of more general visuoperceptual or face processing deficits. Indeed, she had normal performance on visuoperceptual tests, produced a perfect copy of the Rey-Osterreith complex figure, and flawless performance on a test of famous face identification.

In the midst of her profound verbal and non-verbal memory impairments, her recognition memory performance for topographical scenes, unknown buildings, and landscapes was remarkably intact. Moreover, her ability to recall familiar routes and learn new ones through a complex virtual reality town was also normal. Her spatial learning skills and mazes performance were also preserved. Despite preservation of many aspects of topographical memory, intact geographical knowledge was restricted only to the United Kingdom.

As far as we are aware, this study is the first to document the sparing of topographical memory in the context of profound non-verbal memory loss which includes both recognition memory for unfamiliar faces and recall of an abstract visual design. These findings support the notion that topographical memory is subserved by a system separable from that subserving the memory for unfamiliar faces and abstract visual designs.

At the first analysis, it is not immediately clear why such differential patterns of performance are seen across tasks that might be thought to have similar visuoperceptual and spatial requirements. For example, memory for a complex abstract visual design requires visuoperceptual analysis and the processing and recall of spatial relations. Arguably, these abilities are required to an even greater extent in the learning of new routes. Despite this, the patient could not recall an abstract visual design, but quite clearly had no difficulty in recalling routes she had travelled, or in learning new routes. It is possible that her locomotion along and experience of local or national routes recruits a specialised processing channel that integrates visual and somaesthetic information about large topographical items ${ }^{27}$ perhaps in an allocentric (world centred) spatial framework. ${ }^{28}$ Recall of abstract visual designs is possibly processed by a different system concerned with the egocentric (person centred) manipulation of spatial configurations or icons that are essentially devoid of real world experience. ${ }^{18}$

From this position, it could be argued that topographical scenes (particularly unfamiliar), buildings, and landscapes are complex designs that should be processed as egocentric configurations and so be impaired in our patient. However, these topographical stimuli represent important anchor items that facilitate the construction and use of a "cognitive map" of a spatially extended area. ${ }^{28}$ In line with this, cognitive models of environmental learning commonly ascribe a significant role to buildings and landmarks as initial anchor points in topographical memory development. ${ }^{29}{ }^{30}$ For example, it has been shown that topographical stimuli play a crucial part in route learning because effectively they specify the person's location. ${ }^{3132}$ Thus we could speculate that topographical scenes, buildings, and landmarks activate important aspects of the topographical memory system in a similar manner to the recall and learning of complex routes. As the patient can process routes, she can use the same system to also process topographical stimuli.

A recent functional neuroimaging study found evidence in support of the position that landmarks activate most of the topographical memory circuit that is also activated by the 
memory for complex routes. Maguire et $a l^{33}$ measured changes in $\mathrm{rCBF}$ (regional cerebral blood flow) with PET while subjects recalled familiar routes around London in one task, and while recalling famous world landmarks in another. Importantly, the landmarks that were recalled were ones that the subjects were familiar with but had never visited, so landmark recall was not confounded by location information about position within a large scale spatial layout. They found that the pattern of increased brain activity associated with the recall of routes and landmarks was very similar. This included extrastriate regions, bilateral occipitotemporal areas, and bilateral parahippocampal gyrus activation. The involvement of common brain regions in routes and landmarks memory suggests that the same topographical memory system is activated when processing both routes and landmarks.

Given our patient's preserved topographical memory skills, how can we account for her pattern of performance on geographical knowledge tests? In the context of the limited amount of testing carried out, her severe language and verbal memory impairments and the limited amount of information available regarding her premorbid knowledge of the places considered, we merely offer a tentative suggestion. We have argued that our patient remains capable of utilising a system that integrates information about large topographical items as a consequence of locomotion around these objects. The preservation of this system may explain the patient's intact performance on the location of London landmarks test; she is likely to have visited most of these landmarks. From this position, it might be suggested that the patient would be severely impaired in locating cities within countries; it is unlikely that the representation of these items could be achieved during locomotion. ${ }^{18}$ In line with this, the patient was certainly severely impaired on city location in Europe and the world, and on the north/south world test. She performed at the lower limit of the control range for both city location in the United Kingdom and the north/ south United Kingdom test. This pattern of apparent preservation is difficult to interpret. It is possible that her performance was affected by an interaction between the relatively few stimuli used and the relative insensitivity of these measures. Unfortunately a more far reaching examination of these issues was precluded in this case.

The neuropsychological literature has often $^{15} 16^{34}$ but not always ${ }^{13} 35$ implicated the right medial temporal region in mediating topographical memory. In a recent paper, McCarthy et $a l^{15}$ speculated that the storage and processing of place knowledge may be closely linked with spatial skills dependent on the right hemisphere. Functional brain imaging studies using PET and functional MRI in neurologically intact people, have confirmed that there is significant neuronal response in the right medial temporal region during topographical memory tasks. ${ }^{26}{ }^{33} 36-38$ Neuroradiological findings in our patient show a marked contrast between her left and right medial tem- poral lobes. The left temporal lobe is grossly atrophic relative to the right. The right temporal lobe seems less affected particularly in the medial and more posterior regions. These findings are compatible with the literature on the anatomy of topographical memory.

In conclusion, this study shows the complete dissociability of topographical memory from verbal memory. Moreover, it seems that the neural system which is responsible for implementing topographical memory is independent of that implementing other aspects of nonverbal memory such as unfamiliar faces and abstract visual designs. Moscovitch and Umilta $^{39}$ have suggested that the investigation of the selective preservation of cognitive functions, in this case topographical memory, allows the determination of its degree of information encapsulation. Our findings are compatible with the notion that topographical memory is an information encapsulated module distinct and separable from the non-verbal memory systems involved in unfamiliar faces and abstract designs. Given the critical necessity of navigating in the world for both humans and animals, it is perhaps not surprising that topographical memory can continue to operate despite the malfunctioning of a central repository of general knowledge.

We thank Dr Martin Rossor for his permission to study this We thank Dr Martin Rossor for his permission to study this Burgess and Jim Donnett, and Professor John O'Keefe for their work on computer simulated environments. We thank Professors C Frith and T Shallice, and Dr P Rudge for helpful comments. We also thank N Smith for collecting control data. EAM ments. We also thank N Smith for colle
is supported by the Wellcome Trust.

1 Milner B. Interhemispheric differences in the localisation of psychological processes in man. Br Med Bull 1971;27:2727.

2 Pigott S, Milner B. Memory for different aspects of complex visual scenes after unilateral temporal-or frontal-lobe resection. Neuropsychologia 1993;31:1-15.

3 Warrington EK. Recognition memory test. Windsor: NFERNelson, 1984

4 Frisk V, Milner B. The role of the left hippocampal region in the acquisition and retention of story content. Neuropsychologia 1990;28:349-59.

5 Hornak J, Oxbury S, Oxbury J, et al. Hemifield-specific visual recognition memory impairments in patients with visual recognition memory impairments in patients with 35:1311-5.

6 Jones-Gotman M. Memory for designs: the hippocampal contribution. Neuropsychologia 1986;24:193-203.

7 Paterson A, Zangwill OL. Disorders of visual space perception associated with lesions of the right cerebral hemisphere. Brain 1944;67:331-58.

8 Pallis CA. Impaired identification of faces and places with agnosia for colours. Report of a case due to cerebral embolism. F Neurol Neurosurg Psychiatry 1955;18:218-24.

9 Benton AL. Disorders of spatial orientation. In: Viken PJ, Bruyn GW, eds. Handbook of clinical neurology. Amsterdam: North-Holland, 1969;3:212-28.

10 Aimard G, Vighetto A, Confavreux C, et al. La desorientation spatiale. Revue Neurol 1981;137:97-111.

11 Landis T, Cummings JL, Benson DF, et al. Loss of topographic familiarity. An environmental agnosia. Arch Neurol 1986;43:132-6.

12 Clarke S, Assal G, De Tribolet N. Left-hemisphere strategies in visual recognition, topographical orientation and time planning. Neuropsychologia 1993;31:99-113.

13 Bottini G, Cappa S, Geminiani G, et al. Topographic disorientation - a case report. Neuropsychologia 1990;28: $309-12$

14 Hublet C, Demeurisse G. Pure topographical disorientation due to a deep-seated lesion with cortical remote effects. Cortex 1992;28:123-8.

15 McCarthy RA, Evans JJ, Hodges JR. Topographic amnesia: spatial memory disorder, perceptual dysfunction, or category specific semantic impairment? f Neurol Neurosurg Psychiatry 1996;60:318-25.

16 Maguire EA, Burke T, Phillips J, et al. Topographical disorientation following unilateral temporal lobe lesions in entation following unilateral temporal lobe
humans. Neuropsychologia 1996;34:993-1001.

17 Whiteley AM, Warrington EK. Selective impairment of topographical memory: a single case study. F Neurol Neurosurg Psychiatry 1978;41:575-8. 
18 Incisa della Rocchetta A, Cipolotti L, Warrington EK Topographical disorientation: selective impairment of Topographical disorientation: selective

19 Evans JJ, Heggs AJ, Antoun N, et al. Progressive prosopagnosia associated with selective right temporal lobe atrophy: a new syndrome. Brain 1995;118:1-13

20 Warrington EK, James M. The visual object space perception battery. Bury St Edmunds: Thames Valley Test Company, 1991.

21 Warrington EK, McKenna P, Orpwood L. Single word comprehension: a concrete and abstract word synonym test. Neuropsychological Rehabilitation 1998;8:143-54.

22 Clegg F, Warrington EK. Four easy memory tests for older adults. Memory 1994;2:167-82.

23 Corsi PM. Human memory and the medial temporal lobe region of the brain [PhD thesis]. Montreal: McGill University, 1972 .

24 De Renzi E, Faglioni P, Villa P. Topographical amnesia. $\mathcal{F}$ Neurol Neurosurg Psychiatry 1977;40:498-505.

25 Warrington EK The Camden memory tests. Hove, East Sussex: Psychology Press, 1996.

26 Maguire EA, Burgess N, Donnett JG, et al. Knowing where, and getting there: a human navigation network. Science 1998;280:921-4.

27 McNaughton BL, Leonard B, Chen L. Corticalhippocampal interactions and cognitive mapping: a hypothesis based on reintegration of the parietal and inferotemporal pathway for visual processing. Psychobiology 1989;17:230-5

28 O'Keefe J, Nadel L. The hippocampus as a cognitive map. Oxford: Oxford University Press, 1978

29 Hart RA, Moore GT. The development of spatial cognition: a review. In: Downs $\mathrm{R}$, Stea $\mathrm{D}$, eds. Image and environment. Chicago: Aldine, 1973.
30 Siegal AW, White SH. The development of spatial representation of large-scale environments. In: Reese HW, ed. Advances in child development and behavior. Vol 10. New York: Academic Press, 1975.

31 Presson CC. The development of landmarks in spatial memory: the role of differential experience. 7 Exp Child Psychol 1987;44:317-34.

32 Tlauka M, Wilson PN The effect of landmarks on route-learning in a computer-simulated environment. fournal of Environmental Psychology 1994;14:305-13.

33 Maguire EA, Frackowiak RSJ, Frith CD. Recalling routes around London: activation of the right hippocampus in taxi around London: activation of the right
drivers. $\mathcal{F}$ Neurosci $1997 ; 17: 7103-10$

34 Habib M, Sirigu A. Pure topographical disorientation: a definition and anatomical basis. Cortex 1987;23:73-85.

35 Takahashi N, Kawamura M, Shiota J, et al. Pure topographic disorientation due to right retrosplenial lesion. Neurol 1997;49:464-9.

36 Aguirre GK, Detre JA, Alsop DC, et al. The parahippocampus subserves topographical learning in man. Cereb Cortex 1996;6:823-9.

37 Maguire EA, Frackowiak RSJ, Frith CD. Learning to find your way- a role for the human hippocampal region. Proc your way - a role for the human hippocampal
Royal Soc Lond B Biol Sci 1996;263:1745-50.

38 Maguire EA, Burgess N, Donnett JG, et al. Knowing where things are: parahippocampal involvement in encoding object locations in virtual large-scale space. Fournal of Cognitive Neuroscience 1998;10:61-76.

39 Moscovitch M, Umilta C. Modularity and neuropsychology: modules and central processes in attention and memory. In: Schwartz MF, ed. Modular deficits in Alzheimers-type dementia. Cambridge: MIT Press 1990:1- 